\title{
Scleroglucan and guar gum: The synergistic effects of a new polysaccharide system
}

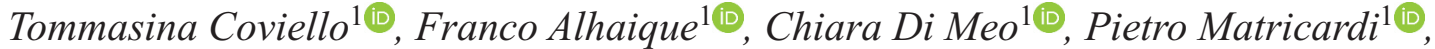

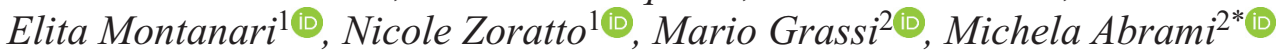 \\ ${ }^{1}$ Department of Drug Chemistry and Technologies, Sapienza University of Rome, Piazzale Aldo Moro 5, 00185 Roma, Italy \\ ${ }^{2}$ Department of Engineering and Architecture, University of Trieste, via Alfonso Valerio 1, 34127 Trieste, Italy
}

Received 8 September 2021; accepted in revised form 24 November 2021

\begin{abstract}
Scleroglucan (Sclg) and guar gum (GG) are capable of giving gels in the presence of borax. This study focuses on how a mixed system of the two polysaccharides can be affected by the addition of borax. The anisotropic swelling behavior of tablets obtained by compression of the freeze-dried new gel system is also investigated and compared to that of Sclg and GG alone. Rheological characterization evidences a synergistic effect in terms of critical time, mesh size, as well as crosslinking density. Also creep recovery experiments, carried out in the presence of borax, show a synergistic effect: when the polymers are mixed, quite low compliance was estimated in comparison to that of Sclg and GG. On the other side, the flexible chains of GG induce the self-healing properties of the mixed gel system since the rigid, triple helix of Sclg does not show such peculiar characteristics.

The deep insight into the physico-chemical properties of the new hydrogel system can play a fundamental role in optimizing its practical application (e.g., in drug delivery, cosmetic products, human tissue repair, wound dressing, and food staff).
\end{abstract}

Keywords: bioplolymers, rheology, scleroglucan, guar gum, water uptake

\section{Introduction}

Scleroglucan (Sclg) is a well-known water-soluble polysaccharide produced by fungi of the genus Sclerotium. It consists of a main chain of $(1 \rightarrow 3)$-linked $\beta$-D-glucopyranosyl units bearing, every third unit, a single $\beta$-D-glucopyranosyl unit linked $(1 \rightarrow 6)$. It is also well known that Sclg assumes a triple-stranded helical conformation in aqueous solution, while in methylsulphoxide or at high $\mathrm{pH}$ values $(\mathrm{pH}>13.5)$, it assumes a single coiled disordered conformation $[1,2]$. Due to its peculiar properties, Sclg was used for several commercial applications (food, paints, cosmetics, secondary oil recovery, ceramic glazes, etc.) [3], and it was also investigated for modified/ sustained release formulations and ophthalmic preparations [4-6].
Guar gum (GG) is a neutral galactomannan, extracted from the seeds of Cyamopsis tetragonoloba. It consists of a linear backbone of $\beta(1 \rightarrow 4)$-linked D-mannopyranose units (Man) with the presence of randomly attached $\alpha(1 \rightarrow 6)$-linked galactopyranose units (Gal) as side chains [7] that lead to a polymer soluble in water [8]. The mannose to galactose units $(M / G)$ ratio is variable, depending on climate variations (from 1.5:1 to 1.8:1). Being GG a low-cost polymer and being capable of producing highly viscous solutions even at low concentrations, it finds important applications in food [9], in oil recovery [10] and in personal care industries [11]. GG assumes a flexible coil conformation in aqueous solution as evidenced by the Mark-Houwink-Sakurada exponent and by the relatively low value of its characteristic

\footnotetext{
${ }^{*}$ Corresponding author, e-mail: michela.abrami@dia.units.it
} (C) BME-PT 
ratio and persistence length [12]. The high viscosity of GG solutions arises from the high molecular weight of the polymer (up to 2 million and even more) [13] and from intermolecular associations (entanglements) due to the presence of hydrogen bonds. GG, cross-linked with glutaraldehyde, was proposed for colon delivery [14], and it was also tested as a matrix for oral solid dosage forms [15].

It is well known that borax is a crosslinker for polymers bearing hydroxyl groups. However, the type of linkages is still debated, and so far, two main models have been proposed. According to the most popular one, only pure chemical cross-links occur between the polymeric chains and borax [16] as suggested in the case of GG. According to the other model, the borax ions hold together the polymeric chains by means of mixed physical/chemical linkages. This model, formerly proposed for poly(vinyl alcohol) [17], was also suggested for Sclg [18, 19].

The complex between GG and borate was previously studied in detail by several authors [20,21]: the effect of polymer and borate concentrations, temperature, environmental $\mathrm{pH}$ conditions, and GG molecular weight on the peculiar rheological properties, detected by the frequency dependence of relaxation spectra, were investigated. Furthermore, the study of the cross-linking reaction of borate ions with GG, carried out by means of NMR spectroscopy, allowed estimating the values of complexation equilibrium constants and the complexation enthalpy at various experimental conditions [16, 22-24]. Similarly, specific investigations on the rheological properties of the schizophyllan/borate system were reported (schizophyllan and Sclg possess the same repeating unit) in other papers $[25,26]$. Both polymers, GG and Sclg, interact with borax leading to a three-dimensional network that, besides the intrinsic differences between the two polymers, shows a peculiar anisotropic elongation during swelling when tablets of these two systems are prepared. In particular, GG and Sclg show different important characteristics: (a) GG dissolves in water as a random coil while Sclg exhibits a triple helix conformation in aqueous solution with a persistence length of about $200 \mathrm{~nm}$ $[1,27]$; (b) borax promotes rapid gelation of GG [28] by means of cross-links characterized by a lifetime of the order of seconds [29], leading to self-healing properties of the network. On the other side, Sclg requires several hours for gelation in the presence of borax and no self-healing occurs. Nevertheless, both
GG and Sclg, in the presence of borax, are capable of giving self-sustaining gels [30]. The interaction with borax takes place in a different way. In the case of Sclg, borax promotes mixed (chemical and physical) interactions among triplexes while in the case of GG, borax forms reversible chemical linkages among chains. Molecular dynamics simulation and AFM images indicate that the borax groups increase the stiffness of GG leading to a system more similar to that of $\mathrm{Sclg} / \mathrm{borax}(\mathrm{Sclg} / \mathrm{b})$.

During GG swelling, the labile nature of the borax cross-links makes the inter-chain interactions able to undergo the needed rearrangement, similar to that of Sclg, where full chemical bridges are not present. These similarities explain the quite unexpected parallel swelling behavior of GG and Sclg in the presence of borax [18, 19, 30].

Thus, it appears interesting to investigate the viscometric/mechanical and physico-chemical properties of the system obtained by mixing Sclg and GG and adding borate ions as cross-linking agents. The aim of this work was to characterize the new Sclg-GG/b system resorting to three different approaches, rheology, Low Field NMR (LF NMR), and water uptake experiments. The joint use of these approaches provides more complete information about the polymeric chain architectures (polymeric networks), also in terms of mesh size estimation, a very important parameter for the performances of the hydrogels when used for industrial and/or pharmaceutical applications.

In addition, the characteristics of the new Sclg-GG/b system were compared with those of the $\mathrm{Sclg} / \mathrm{b}$ and GG/b samples.

\section{Experimental section}

\subsection{Materials}

Guar gum (GG) was provided by CarboMer (San Diego, USA). The ratio between mannose and galactose was estimated to be 1.5 by ${ }^{1} \mathrm{H}$ NMR (Brucker AVANCE AQS 600 spectrometer, operating at $600.13 \mathrm{MHz}$ and $\left.70^{\circ} \mathrm{C}\right)$. The molecular weight $\left(1.2 \cdot 10^{6}\right)$ was estimated by viscometric measurements carried out at $25^{\circ} \mathrm{C}$ (Instrument Schott AVS 370, Lauda, Germany, with a water bath Lauda 0.15 T, Ubbelohde capillary viscometer Type No 53101, capillary diameter $=0.54 \mathrm{~mm}$, Schott-Geräte for dilution sequences).

Scleroglucan (Sclg) was provided by Degussa (Germany). The molecular weight $\left(1.1 \cdot 10^{6}\right)$ was estimated 
by viscometric measurements at $25^{\circ} \mathrm{C}$ in $0.01 \mathrm{M}$ $\mathrm{NaOH}$ (for experimental details, see above).

The two polymers' molecular weight was evaluated according to the Mark-Houwink-Sakurada equation, found in the literature for GG samples [2] and Sclg samples [12].

Sodium tetraborate decahydrate, borax (ACS reagent $\geq 99.5 \%$ ), was a Sigma-Aldrich (Germany) product. Distilled water was always used.

\subsection{Polymer purification}

A given amount of polymer (GG and Sclg) was dissolved in distilled water (polymer concentration, $c_{\mathrm{p}}=$ $0.5 \% \mathrm{w} / \mathrm{v})$. GG samples were kept under magnetic and mechanical stirring at $60^{\circ} \mathrm{C}$ for $24 \mathrm{~h}$ and then at room temperature for 24 additional hours [31]. Sclg samples were kept under magnetic and mechanical stirring for $24 \mathrm{~h}$ at room temperature.

The resulting solutions were exhaustively dialyzed at $7{ }^{\circ} \mathrm{C}$ against distilled water with dialysis membranes (cut-off 12000-14000) and then freeze-dried. The lyophilized products were stored in a desiccator until use.

\subsection{Hydrogel preparations}

For the mixed hydrogel, given amounts of GG and Sclg $(1: 1, w: w)$ were dissolved in water for $24 \mathrm{~h}$.

A given amount of GG or Sclg (200 mg for the water uptake experiments and $35 \mathrm{mg}$ for the rheological analysis and for NMR measurements; $c_{\mathrm{p}}=0.7 \% \mathrm{w} / \mathrm{v}$ ) was dissolved in water for $24 \mathrm{~h}$.

\subsection{Mixed hydrogels and tablet preparations}

For the preparation of the mixed hydrogels, an appropriate amount of each polymer ( $100 \mathrm{mg}$ of each polymer for the water uptake experiments and $\sim 18 \mathrm{mg}$ of each polymer for the rheological analysis and NMR measurements; total polymer concentration, $c_{\mathrm{p}}=0.7 \% \mathrm{w} / \mathrm{v}$ ) was magnetically stirred in water for $24 \mathrm{~h}$. Then, the calculated amount (i.e., moles of borax/sum of moles of repeating units of each polymer $=1$ for tablet samples) of a $0.1 \mathrm{M}$ borax solution was added. The systems were left under magnetic stirring for $5 \mathrm{~min}$. During salt addition, due to the self-buffering effect of borax, the $\mathrm{pH}$ value was constant $(\mathrm{pH}=9.0)$.

The obtained samples (total polymer concentration, $\left.c_{\mathrm{p}}=0.7 \% \mathrm{w} / \mathrm{v}\right)$ were kept 2 days at $7{ }^{\circ} \mathrm{C}$ for gel setting. For tablet preparation, the hydrogels were previously freeze-dried and then compressed using an
IR die (Perkin-Elmer hydraulic press) and applying a force of $5.0 \mathrm{kN}$ for $30 \mathrm{~s}$. The weight of the tablets was $230 \pm 10 \mathrm{mg}$; their diameter was $13.0 \pm 0.1 \mathrm{~mm}$, and the thickness was $1.4 \pm 0.2 \mathrm{~mm}$.

For an appropriate comparison, tablets of $\mathrm{Sclg} / \mathrm{b}$ and $\mathrm{GG} / \mathrm{b}$ were also prepared according to the procedure described above.

\subsection{Water uptake and dimensional increase studies}

The swelling of tablets was carried out by soaking the tablets in $200 \mathrm{ml}$ of distilled water at $37^{\circ} \mathrm{C}$. At fixed time intervals, the tablets were withdrawn, the excess of water was removed with soft filter paper for $5 \mathrm{~s}$, and then the corresponding thickness $(h)$ and diameter variations were determined by screw gauge with an accuracy of $\pm 0.1 \mathrm{~mm}$. At the same time, the weight $(w)$ changes were also monitored.

All analyses were performed on three replicate samples. Since tablet diameters did not increase significantly during the experiments, only the recorded mean values of the relative increase of weight and thickness $\left(\left(w-w_{0}\right) / w_{0}\right.$ and $\left.\left(h-h_{0}\right) / h_{0}\right)$ were reported. In all cases, variations of the experimental values were below $10 \%$ of the mean.

\subsection{Rheological characterization}

The rheological characterization was carried out at $25^{\circ} \mathrm{C}$ using a controlled stress rheometer (Haake Mars III) equipped with a Peltier temperature control system. A glass solvent trap with water was used to create a saturated atmosphere around the sample in order to minimize solvent evaporation.

Two measuring configurations were used. The first, devoted to the samples without borax, consisted in a cone-plate device (C60/1 Ti with a cone diameter of $60 \mathrm{~mm}$ and a cone angle of $1^{\circ}$ ) while a grained plate-plate device (Haake PP35Ti: diameter $=$ $35 \mathrm{~mm}$; the gap between plates $=1-3 \mathrm{~mm}$ ) was used for the samples with borax, in order to prevent wall slippage phenomena [32]. To perform the measurements on borax added samples, the hydrogels, obtained with a thickness of 1.0-3.0 mm, were removed with the aid of a small spatula from the beaker in which they had settled, and they were laid with care on the lower plate of the rheometer. Then, the upper plate was lowered until it reached the sample surface. Gap-setting optimization was undertaken according to a procedure described elsewhere [33]. 
Rheological properties were studied by oscillatory tests. In particular, the samples' linear viscoelastic regions were assessed at $1 \mathrm{~Hz}$ by stress sweep experiments. Frequency sweep tests were carried out in the frequency $(f)$ range of $0.01-100 \mathrm{~Hz}$ at a constant deformation $\gamma=0.05$ (well inside the linear viscoelastic range for all the studied hydrogels). In addition, creep-recovery experiments were performed by applying, first, constant shear stress $(\tau)$ for $5 \mathrm{~min}$ and then measuring the resulting changes in strain $(\gamma)$. Then, the recovery after removing stress was monitored over a further period of $5 \mathrm{~min}$. The values of the applied stress were increased systematically, from 0.5 to $100 \mathrm{~Pa}$. Creep-recovery curves were reported in terms of compliance $(0=\gamma / \tau)$.

The experimental storage $\left(G^{\prime}\right)$ and loss $\left(G^{\prime \prime}\right)$ moduli, obtained by frequency sweep tests, were fitted by the generalized Maxwell model (Equation (1), (2)):

$G^{\prime}=G_{\mathrm{e}}+\sum_{\mathrm{i}=1}^{\mathrm{N}} \frac{g_{\mathrm{i}} \lambda_{\mathrm{i}}^{2} \omega^{2}}{1+\lambda_{\mathrm{i}}^{2} \omega^{2}}$

$$
G^{\prime \prime}=\sum_{\mathrm{i}=1}^{\mathrm{N}} \frac{g_{\mathrm{i}} \lambda_{\mathrm{i}} \omega}{1+\lambda_{\mathrm{i}}^{2} \omega^{2}}
$$

where $\omega$ is the pulsation (equal to $2 \pi f$ ), $G_{\mathrm{e}}$ is the elastic constant of the purely elastic element while $g_{\mathrm{i}}$ and $\lambda_{i}$ are, respectively, the elastic constant and the relaxation time of the $i^{\text {th }}$ generalized Maxwell model element.

In the linear viscoelastic range, the experimental creep data were fitted by the compliance expression deriving from the generalized Maxwell model (Equation (3)):

$J(t)=\left(G_{\mathrm{e}}+\sum_{\mathrm{i}=1}^{\mathrm{N}} \frac{\lambda_{\mathrm{i}} g_{\mathrm{i}}}{t+\lambda_{\mathrm{i}}}\right)^{-1}$

where $t$ is time.

Equations (1), (2) and (3) were fit to experimental data, assuming that the $\lambda_{\mathrm{i}}$ values were scaled by a factor of $10\left(\lambda_{\mathrm{i}+1}=10 \cdot \lambda_{\mathrm{i}}\right)$ [32]. $N$ determinations were performed according to a statistical procedure based on the minimization of the product $\left((N+2) \cdot \chi^{2}\right)$ [34]. $(N+2)$ represents the number of model fitting parameters and $\chi^{2}$ is the sum of the squared errors between model and experimental data.

The sample shear modulus $G$ was evaluated as the sum of all elastic constants $\left(G=G_{\mathrm{e}}+\sum g_{\mathrm{i}}\right)[35,36]$. Relying on $G$ knowledge, Flory theory [37] allowed the evaluation of the polymeric network cross-link density, $\rho_{\mathrm{x}}$, defined as the moles of junction points between different polymeric chains per hydrogel unit volume (Equation (4)):

$\rho_{\mathrm{x}}=\frac{G}{R T}$

where $R$ is the universal gas constant and $T$ is the absolute temperature. Finally, the equivalent network theory [38] enabled the determination of the average mesh size $\xi$ of the sample polymeric networks (Equation (5)):

$\xi=\sqrt[3]{\frac{6}{\pi \rho_{\mathrm{x}} N_{\mathrm{A}}}}$

were $N_{\mathrm{A}}$ is the Avogadro number.

\subsection{Low field NMR characterization}

LF-NMR measurements were performed at $25^{\circ} \mathrm{C}$ with a Bruker Minispec mq20 (0.47 T, Germany) equipment, according to the $C P M G$ sequence (CarrPurcell-Meiboom-Gill) [39]

$\left\{90^{\circ}\left[-\tau-180^{\circ}-\tau(\right.\right.$ echo $\left.\left.)\right] n-T_{\mathrm{R}}\right\}$, with an $8.36 \mu \mathrm{s}$ wide $90^{\circ}$ pulse, $\tau=250 \mu$ s and a $T_{\mathrm{R}}$ (sequence repetition rate) equal to $10 \mathrm{~s}$. Each spin-echo decay had $n$ points, and it was repeated 36 times (number of scans).

The relaxation process was described by the sum of exponential terms, each one characterized by a different time decay constant $\left(T_{2 \mathrm{i}}\right)$ and weight $\left(A_{\mathrm{i}}\right)$ [40] (Equation (6)):

$$
I(t)=\sum_{\mathrm{i}=1}^{\mathrm{m}} A_{\mathrm{i}} \mathrm{e}^{-\left(\mathrm{t} / \mathrm{T}_{2 \mathrm{i}}\right)}
$$

where $I(t)$ is the dimensionless signal amplitude that becomes negligible at the end of the relaxation process. The average relaxation time $\left(T_{2 \mathrm{~m}}\right)$ and the average inverse relaxation time $\left(\left(1 / T_{2}\right)_{\mathrm{m}}\right)$ can be defined by Equation (7):

$$
\begin{aligned}
& T_{2 \mathrm{~m}}=\frac{\sum_{\mathrm{i}=1}^{\mathrm{m}} A_{\mathrm{i}} T_{2 \mathrm{i}}}{\sum_{\mathrm{i}=1}^{\mathrm{m}} A_{\mathrm{i}}} \rightarrow\left(\frac{1}{T_{2}}\right)_{\mathrm{m}}=\frac{\sum_{\mathrm{i}=1}^{\mathrm{m}} \frac{A_{i}}{T_{2 \mathrm{i}}}}{\sum_{\mathrm{i}=1}^{\mathrm{m}} A_{\mathrm{i}}} \rightarrow \\
& \rightarrow A_{\mathrm{i} \%}=100 \frac{A_{\mathrm{i}}}{\sum_{\mathrm{i}=1}^{\mathrm{m}} A_{\mathrm{i}}}
\end{aligned}
$$

The number, $m$, of exponential decays appearing in Equation (6) was determined by a statistical procedure based on the minimization of the product $\left(2 \cdot N \cdot \chi^{2}\right)[34]$ where $\chi^{2}$ is the sum of the squared errors 
and $2 N$ is the number of model fitting parameters. The $m$ couples $\left(T_{2 \mathrm{i}}, A_{\mathrm{i}} \%\right)$ represent the discrete relaxation time distributions. Quite remarkable, as in the case of polymeric gels, $\xi$ lies in the nanometer range, each $T_{2 \mathrm{i}}$ value is connected to a specific mesh-size of dimension $\xi_{\mathrm{i}}$ (fast diffusion conditions) [40, 41], as shown in Equation (8), according to Abrami et al. [42]:

$\xi_{\mathrm{i}}=\xi\left(\frac{\left(\frac{1}{T_{2}}\right)_{\mathrm{m}}-\frac{1}{T_{2 \mathrm{H}_{2} \mathrm{O}}}}{\frac{1}{T_{2 \mathrm{i}}}-\frac{1}{T_{2 \mathrm{H}_{2} \mathrm{O}}}}\right)$

where $\xi$ is the average mesh size obtained from the rheological characterization, and $\mathrm{T}_{2 \mathrm{H}_{2} \mathrm{O}}$ is the relaxation time of bulk water hydrogen atoms (i.e., water located far from polymer chains) $\approx 3000 \mathrm{~ms}$ at $25^{\circ} \mathrm{C}$, $20 \mathrm{MHz}$ [43].

Another possible way to analyze the relaxation data is to consider in Equation (6) the relaxation times $T_{2 \mathrm{i}}$ fixed in advance by a logarithmic subdivision (200 parts in this case: a finer subdivision was unnecessary) within a suitable relaxation time range (1$10^{4} \mathrm{~ms}$ in this case).

Thus, Equation (6) fitting to experimental data allowed obtaining the 200 unknowns $A_{\mathrm{i}}$. The 200 couples $\left(T_{2 \mathrm{i}}, A_{\mathrm{i} \%}\right)$ constitute the continuous relaxation spectrum (see continuous distributions of Figure 8). Due to the disturbing effect of the data noise, for the fitting procedure of the experimental measure of $I(t)$, it was not possible to apply the $\chi^{2}$ statistic for the minimization of the errors, and therefore a smoothed version, $\chi_{\mathrm{s}}^{2}$, was used [44] (Equation (9)):

$\chi_{\mathrm{s}}^{2}=\chi^{2}+\mu \sum_{\mathrm{i}=1}^{\mathrm{m}-2}\left|A_{\mathrm{i}+2}-2 A_{\mathrm{i}+1}+A_{\mathrm{i}}\right|$

where $\mu$ is the weight of the smoothing terms (second summation in Equation (9)) proposed by Provencher [45]. Although different criteria could be followed for $\mu$ determination, in the present work, the strategy proposed by Wang and Ni [46] was adopted. The chosen $\mu$ value (=150) was that occurring just after the heel (slope variation) of the function $\ln \left\{\chi_{s}\right\} \nu \ln \{\mu\}$.

According to this strategy and Equation (8), the continuous mesh size distribution of our samples $\left(\xi_{\mathrm{i}}\right.$, $\left.A_{\mathrm{i} \%}\right)$ was determined.

\section{Results and discussion}

\subsection{Water uptake}

Usually, a gel swells at the same extent in all directions (isotropic swelling). Nevertheless, quite surprisingly, we observed that tablets of Sclg and
GG, preliminarily cross-linked with borate ions, when soaked in water $\left(37^{\circ} \mathrm{C}\right)$, showed a peculiar anisotropic swelling. This aspect was extensively investigated and published in previous papers $[5,30]$. Despite the very different structures and conformational features of GG and Sclg, also in the case of the blend of the two polymers, the behavior was very similar to that of the starting polymers. Actually, swelling occurred again essentially along one direction. Consequently, the formation of a new mixed and somehow structured network can be assumed. In this sense, it must be added that when the chains of the two polymers are solubilized together, they do not lead to phase separation, thus showing compatibility and the possibility to form a homogeneous solution.

In Figure 1, tablet water uptake $\left(w-w_{0}\right) / w_{0}$ for the new Sclg-GG/b system (Figure 1a) together with the corresponding relative height increase $\left(h-h_{0}\right) / h_{0}$ (Figure 1b) are shown. For an appropriate comparison, the same data, obtained separately with $\mathrm{Sclg} / \mathrm{b}$ and $\mathrm{GG} / \mathrm{b}$, are also given. Better visualization of the anomalous swelling can be acquired from the pictures of Sclg-GG/b tablets swelled for 8 and $24 \mathrm{~h}$, respectively (Figure $1 \mathrm{c}$ and $1 \mathrm{~d}$ ).

\subsection{Rheological characterization}

Firstly, stress/strain sweep tests were executed to determine the limit of the linear viscoelastic field. These tests indicate that the deformation $\gamma=0.05$, chosen to perform the frequency sweep tests, lies in the linear viscoelastic range for all samples. Indeed, the critical deformation value $\left(\gamma_{c}\right)$ is very far bigger, as shown in Table 1.

Figure 2 shows the mechanical spectra obtained by the frequency sweep tests for the systems reported in Table 1. It is clear that GG $0.35 \%$ and GG $0.7 \%$ are solutions, as $G^{\prime}$ is lower than $G^{\prime \prime}$ for all considered frequencies $(f=\omega / 2 \pi)$ (Figures $2 \mathrm{~b}$ and $2 \mathrm{~d}$ ). On the other side, $G^{\prime}$ and $G^{\prime \prime}$ of Sclg-GG $0.7 \%$ and Sclg $0.35 \%$ are almost equal in the entire frequency range $(f=\omega / 2 \pi)$ (Figures $2 \mathrm{c}$ and $2 \mathrm{e}$ ), indicating that such systems are showing the so-called sol-gel transition. $\mathrm{GG} / \mathrm{b}$ 0.7\%, GG/b $0.35 \%$ and Sclg-GG/b $0.7 \%$ (Figures 2b, 2d and 2e) fall in the wide field of weak gel, as $G^{\prime}>G^{\prime \prime}$, but at the lowest frequency $(f=\omega / 2 \pi$, $G^{\prime}$ and $G^{\prime \prime}$ tend to become equal (crossing point). All other systems can be defined as gels since $G^{\prime} \gg G^{\prime \prime}$ and their ratio is substantially constant over the whole investigated $f$ range. It is interesting to underline that 

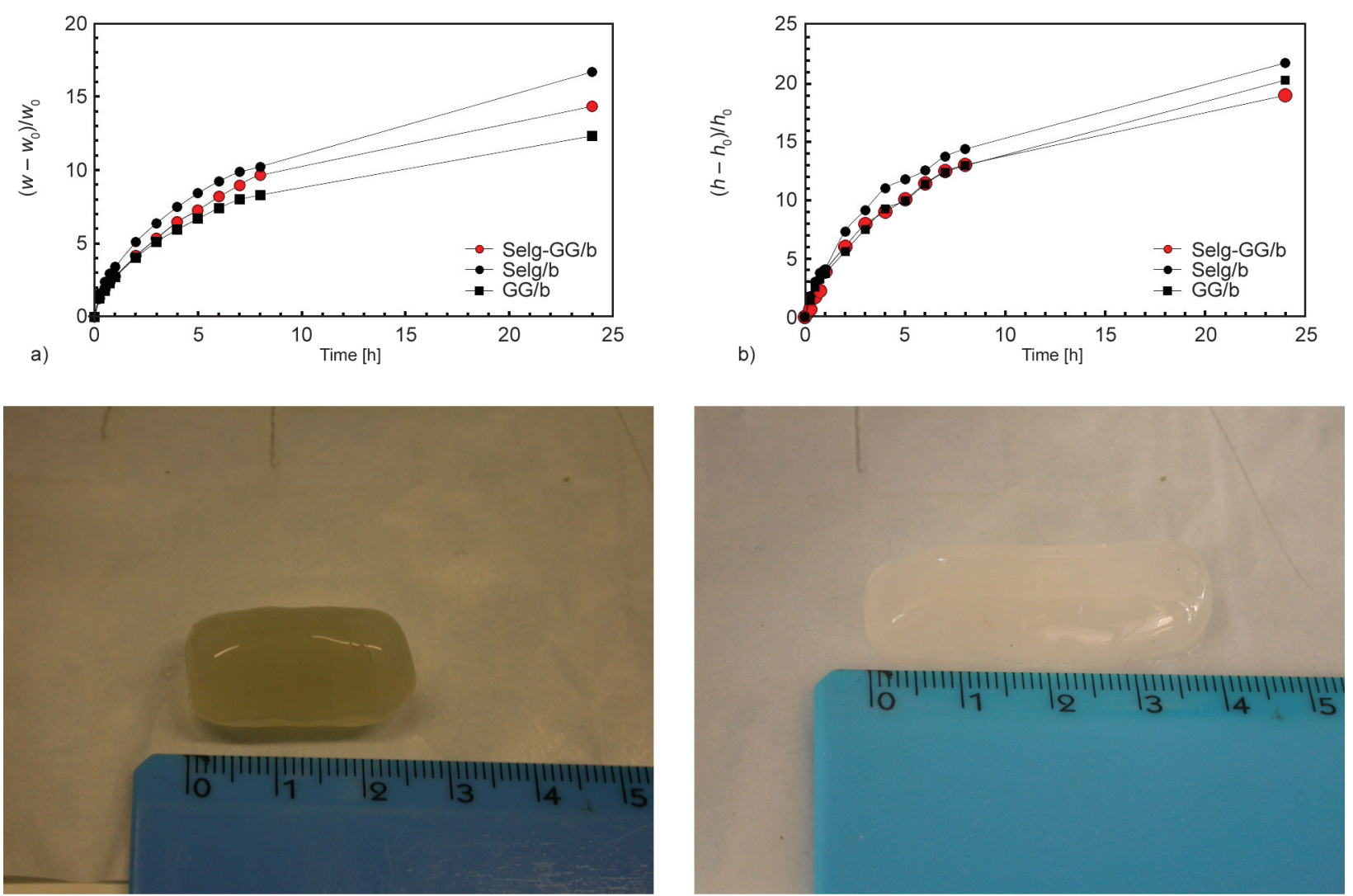

c)

d)

Figure 1. a) Water uptake $\left(w-w_{0}\right) / w_{0}$ and b) relative height increase $\left(h-h_{0}\right) / h_{0}$ from tablets of Sclg-GG/b, Sclg/b, and GG/b as a function of time $\left(c_{\mathrm{p}}=0,7 \%\right)$, distilled water, $\left.37^{\circ} \mathrm{C}\right)$. Experiments were carried out in triplicate, and the obtained values always lay within $10 \%$ of the mean. c) Picture of Sclg-GG/b tablets swelled for $8 \mathrm{~h}$ (c) and $24 \mathrm{~h}$ (d).

the addition of borax reflects in a noticeable variation of system properties, especially for the samples containing GG.

By applying Equations (1), (2) fitting to the mechanical spectra reported in Figure 2 (obviously, solution samples were not considered), it was possible to obtain the parameters listed in Table 2: the shear modulus

Table 1. Limit of the linear viscoelastic range obtained with the stress sweep tests for the studied samples. $\gamma_{\mathrm{c}}, \tau_{\mathrm{c}}$, and $G_{\mathrm{c}}$ are, respectively, the critical values of deformation, stress, and modulus.

\begin{tabular}{|l|c|r|r|l|}
\hline \multicolumn{1}{|c|}{ Sample } & $\begin{array}{c}\boldsymbol{\gamma}_{\mathbf{c}} \\
{[-]}\end{array}$ & $\begin{array}{c}\boldsymbol{\tau}_{\mathbf{c}} \\
{[\mathbf{P a}]}\end{array}$ & $\begin{array}{c}\boldsymbol{G}_{\mathbf{c}} \\
{[\mathbf{P a}]}\end{array}$ & \multicolumn{1}{c|}{$\begin{array}{c}\text { Type of } \\
\text { material }\end{array}$} \\
\hline Sclg $0.35 \%$ & 0.28 & 0.6 & 2.1 & Gel point \\
\hline Sclg/b 0.35\% & 0.55 & 2.9 & 5.3 & Gel \\
\hline GG $0.35 \%$ & 11.40 & 8.2 & 0.7 & Solution \\
\hline GG/b 0.35\% & 1.37 & 13.9 & 10.1 & Gel \\
\hline Sclg 0.7\% & 0.11 & 1.7 & 15.4 & Gel \\
\hline Sclg/b 0.7\% & 0.21 & 5.7 & 27.1 & Gel \\
\hline GG 0.7\% & 1.07 & 5.3 & 5.0 & Solution \\
\hline GG/b 0.7\% & 0.11 & 47.6 & 428.5 & Gel \\
\hline Sclg-GG 0.7\% & 0.69 & 0.9 & 1.3 & Gel point \\
\hline Sclg-GG/b 0.7\% & 0.35 & 13.4 & 38.8 & Gel \\
\hline
\end{tabular}

$G$, the average mesh size $\xi$ of the polymeric network and the number of generalized Maxwell model elements required for a statistically reliable fitting (according to F-test).

Table 2 shows that 2-3 Maxwell elements, plus a purely elastic spring, were necessary to properly describe the viscoelastic properties of the studied polymeric systems. In addition, the comparison of Table 1 and Table 2 indicates the existence of a linear correlation between the shear modulus $(G)$ and the critical modulus $\left(G_{\mathrm{c}}\right)$, as shown in Figure 3. In particular, being the slope of the straight line correlating $G$ and $G_{\mathrm{c}}$ (see caption to Figure 3) close to one, and being the intercept almost zero, we can assume that $G \approx G_{\mathrm{c}}$ for all investigated samples.

A more in-depth evaluation of Figure 2 indicates that the mechanical spectra of the GG and Sclg samples are completely different. Sclg shows the typical behavior of a weak gel at both concentrations, 0.35 and $0.7 \%$, and the effect of borax is just a slight increase of the two moduli. Thus, the number of elastically active chains that contribute to the dynamic modulus is rather low and supports the mixed physical and 

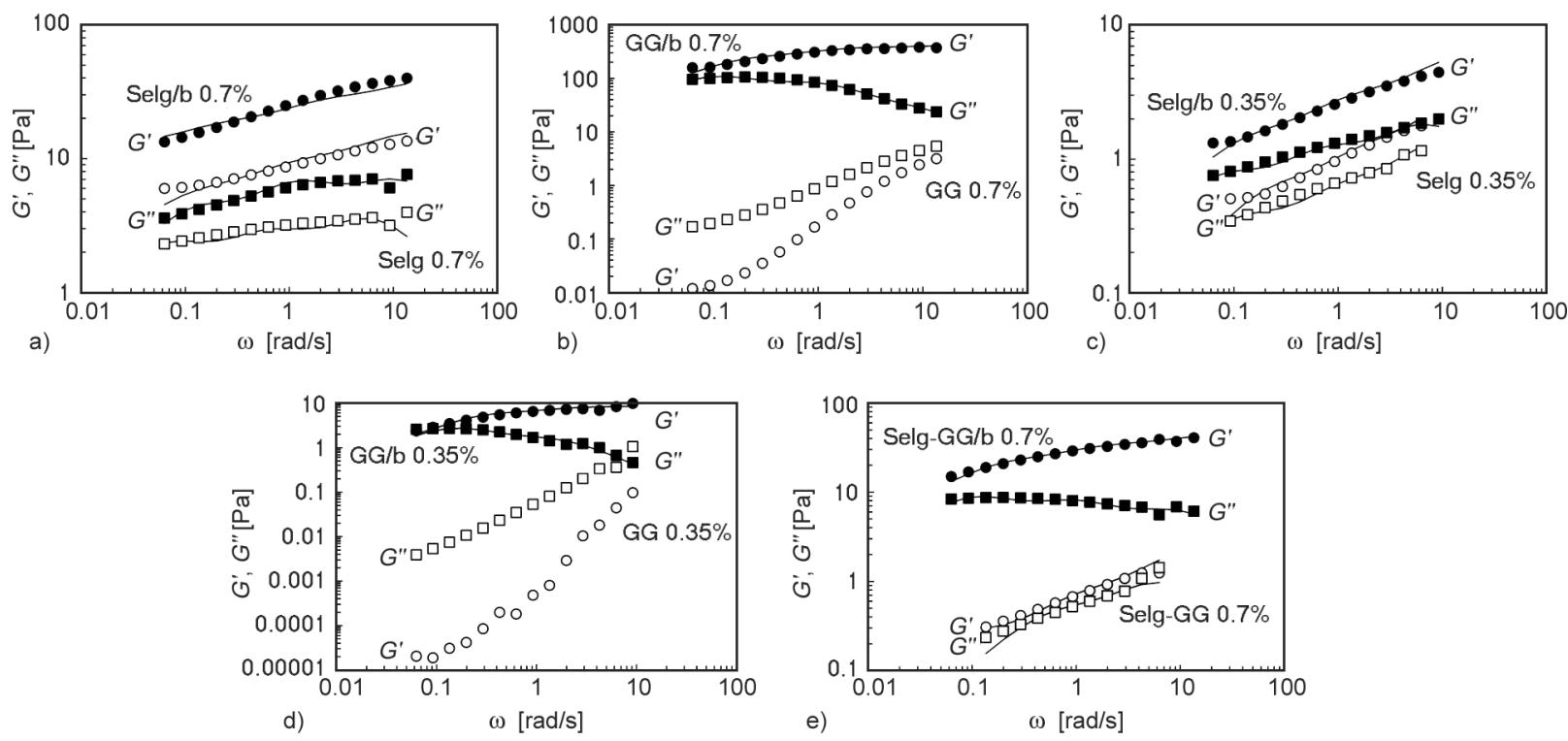

Figure 2. Mechanical spectra of Sclg (a) and GG (b) with borax (closed symbols) and without (open symbols) when polymer concentration $c_{\mathrm{p}}=0.7 \%$. Mechanical spectra of Sclg (c) and GG (d) with borax (closed symbols) and without (open symbols) when polymer concentration $c_{\mathrm{p}}=0.35 \%$. Mechanical spectra of Sclg-GG system (e) with borax (closed symbols) and without (open symbols) for a final polymer concentration $c_{\mathrm{p}}=0.7 \%$ (each polymer $\left.c_{\mathrm{p}}=0.35 \%\right)$. $T=$ $25^{\circ} \mathrm{C}$. Storage modulus, $G^{\prime}$ : circles; loss modulus, $G^{\prime \prime}$ : squares. Continuous lines represent the generalized Maxwell model best fitting (Equations (1) and (2)).

chemical nature of the linkage proposed by the authors between borate ions and hydroxyl groups of the polymer [18].

A different situation is observed for GG at both concentrations $(0.35$ and $0.7 \%)$. The polymer samples have very low values for the two moduli with $G^{\prime \prime}$ always higher than $G^{\prime}$ and both show a strong dependence on the applied frequency. The GG crosslinking by complexation with borate ions leads to an increase in both moduli. A plateau characterized by a weak frequency dependence of $G^{\prime}(\omega)$ and an increase of the storage modulus at least of a factor near three

Table 2. Generalized Maxwell model (Equations (1) and (2)) fitting parameters $\left(G_{\mathrm{e}}, g_{\mathrm{i}}, \lambda_{1}\right)$ and derived parameters (shear modulus $G$ and polymeric network mesh size $\xi$ ) obtained for the studied gels.

\begin{tabular}{|c|c|c|c|c|c|}
\hline Sample & $\begin{array}{c}\lambda_{1} \cdot 10^{2} \\
{[\mathrm{~s}]}\end{array}$ & $\begin{array}{c}G_{\mathrm{e}} \\
{[\mathrm{Pa}]}\end{array}$ & $\begin{array}{c}g_{\mathrm{i}} \\
{[\mathrm{Pa}]}\end{array}$ & $\begin{array}{c}G \\
{[\mathrm{~Pa}]}\end{array}$ & $\begin{array}{c}\xi \\
{[\mathbf{n m}]}\end{array}$ \\
\hline Sclg $0.35 \%$ & $8.8 \pm 0.5$ & $0.15 \pm 0.064$ & $\begin{array}{l}2.60 \pm 1.50 \\
0.74 \pm 0.26 \\
0.55 \pm 0.13\end{array}$ & $4.0 \pm 1.6$ & $125.0 \pm 16.0$ \\
\hline Sclg/b 0.35\% & $26.0 \pm 3.4$ & $0.18 \pm 0.17$ & $\begin{array}{l}2.90 \pm 0.19 \\
1.30 \pm 0.18 \\
1.20 \pm 0.18 \\
\end{array}$ & $6.6 \pm 0.4$ & $106.0 \pm 2.0$ \\
\hline GG/b 0.35\% & $66.0 \pm 8.0$ & $1.27 \pm 0.25$ & $\begin{array}{l}2.10 \pm 0.28 \\
5.00 \pm 0.28\end{array}$ & $8.5 \pm 0.5$ & $97.5 \pm 1.8$ \\
\hline Sclg $0.7 \%$ & $15.7 \pm 2.0$ & $2.60 \pm 0.43$ & $\begin{array}{l}6.30 \pm 0.47 \\
4.00 \pm 0.43 \\
3.80 \pm 0.39\end{array}$ & $16.7 \pm 0.9$ & $78.0 \pm 1.4$ \\
\hline $\mathrm{Sclg} / \mathrm{b}$ 0.7\% & $8.4 \pm 1.0$ & $13.20 \pm 0.57$ & $\begin{array}{r}11.80 \pm 0.75 \\
10.00 \pm 0.60 \\
6.50 \pm 0.58\end{array}$ & $41.6 \pm 1.3$ & $57.4 \pm 0.6$ \\
\hline GG/b $0.7 \%$ & $9.8 \pm 0.8$ & $74.40 \pm 9.50$ & $\begin{array}{r}26.60 \pm 1.70 \\
121.00 \pm 6.70 \\
193.00 \pm 7.50\end{array}$ & $415.0 \pm 14.0$ & $26.6 \pm 0.3$ \\
\hline Sclg-GG $0.7 \%$ & $22.0 \pm 6.3$ & $0.22 \pm 0.06$ & $\begin{array}{l}1.30 \pm 0.21 \\
0.51 \pm 0.16\end{array}$ & $2.0 \pm 0.3$ & $158.0 \pm 7.0$ \\
\hline Sclg-GG/b 0.7\% & $10.0 \pm 3.0$ & $8.90 \pm 2.30$ & $\begin{array}{r}9.90 \pm 1.60 \\
11.40 \pm 1.80 \\
15.30 \pm 2.00\end{array}$ & $45.5 \pm 3.9$ & $56.0 \pm 1.6$ \\
\hline
\end{tabular}




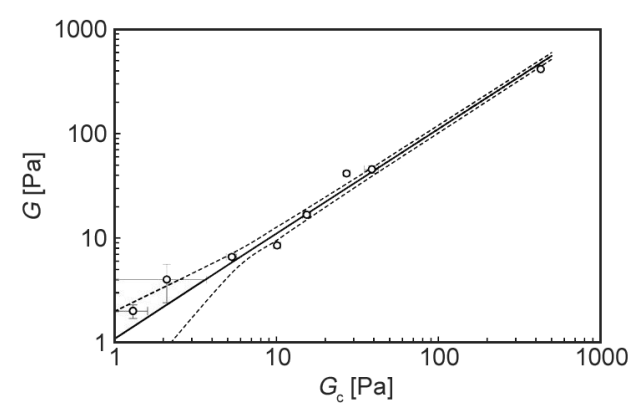

Figure 3. Linear correlation between the shear $(G)$ and the critical modulus $\left(G_{\mathrm{c}}\right)$ (reported in Table 2 and Table 1, respectively). Circles indicate the data, while vertical and horizontal bars represent the standard error. Solid line is the straight line correlating $G$ to $G_{\mathrm{c}}$ :

$\left.G=(1.11 \pm 0.08) \cdot G_{\mathrm{c}}+(-0.027 \pm 0.82) ; r=0.97\right)$, while dashed lines indicate the confidence interval.

can be observed. Furthermore, the $G^{\prime \prime}$ spectra show a maximum and a minimum. These features are similar to those already evidenced for concentrated polystyrene solutions $[47,48]$ and that were attributed to entanglement couplings between molecular chains $[49,50]$. Thus, the curves of loss modulus $v s \omega$ have a maximum $\left(G^{\prime \prime}{ }_{\max }, \omega_{\max }\right)$, and those of the storage modulus has a plateau.

Similar relaxation behaviors were observed for other systems (PVA/borate [51], konjac/borax [52], GG/ borax (in the presence of salts) $[20,21]$ ) and the peculiar shape of the $G^{\prime \prime}$ modulus was ascribed to the labile nature of the chemical cross-links between the borax molecules and the polymeric chains.

The frequency corresponding to the $G^{\prime \prime}{ }_{\text {max }}\left(\omega_{\max }\right)$ is a good indication of the longest relaxation time $\lambda_{\mathrm{r}}$ $\left(\lambda_{\mathrm{r}}=1 / \omega_{\max }\right)$, i.e., the time for a molecule to disengage by a snakelike motion from a tube made up of neighboring chains, as described in the reptation model $[53,54]$. However, the reptation of a polymer- ic chain in the GG/borax sample should be hampered due to the fact that any monomer may be reversibly linked to a neighboring chain by borate ions, leading to a loose reversible gel with temporarily cross-linked chains. In this case, the longest relaxation time represents the reciprocal of the exchange rate for the formation of intermolecular cross-links. In addition, it does not make much sense to assign a single longest relaxation time for the gel. Therefore the frequency $\omega_{\max }$ (corresponding to the maximum of the loss modulus) gives an estimation of the characteristic time of the main relaxation mechanism.

From the experimental data reported in Figure 2, in the case of GG/b at $c_{\mathrm{p}}=0.7 \%$, a $\lambda_{\mathrm{r}} \approx 11 \mathrm{~s}$ was estimated, i.e., the same value found for $\mathrm{GG} /$ borax at similar polymer concentration in $1 \mathrm{M} \mathrm{NaCl}$ [29] and of the same order of magnitude of that for konjac/ borax system $\left(\lambda_{\mathrm{r}} \approx 20 \mathrm{~s}\right)$ [52], but higher than that of PVA/borax $\left(\lambda_{\mathrm{r}} \approx 0.24 \mathrm{~s}\right)$ [55].

The estimated $\lambda_{\mathrm{r}} \approx 11 \mathrm{~s}$ for GG/b at $c_{\mathrm{p}}=0.7 \%, \lambda_{\mathrm{r}} \approx 5 \mathrm{~s}$ for $\mathrm{GG} / \mathrm{b} 0.35 \%$, and $\lambda_{\mathrm{r}} \approx 9 \mathrm{~s}$ for Sclg-GG/b (from the data of Figure 2) can be now compared with the main relaxation times, calculated by applying the Maxwell model and reported in Table $2(9,8,6,6$, and $10 \mathrm{~s}$ respectively), thus showing the good agreement between the two different approaches. Furthermore, when compared to other systems [29, 56, 57], the very low values of relaxation times arise from the lability of cross-links and are related to the peculiarity of the self-healing characteristics of GG/ borax gel, not observed in the Sclg/borax systems. In this sense, it appears important to point out that, also in the case of the mixed systems (Sclg-GG/ borax), the self-healing phenomenon was again observed (Figure 4).

It is quite noticeable that, in the Sclg-GG system, the power-law frequency dependence of the dynamic

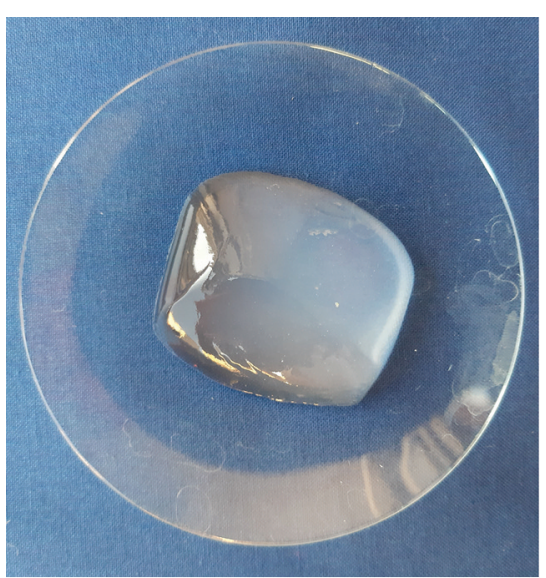

a)

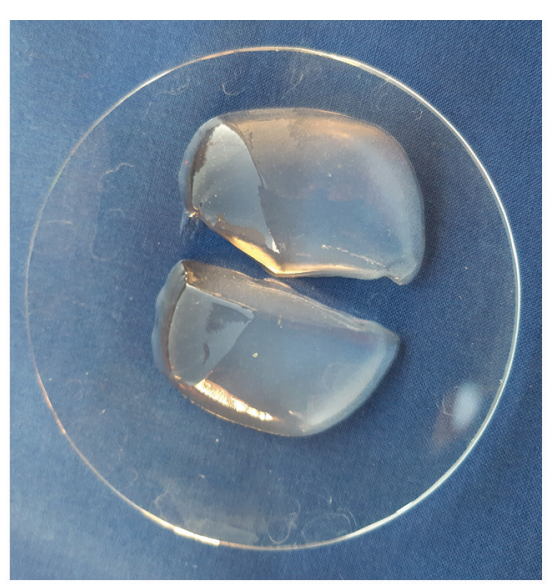

b)

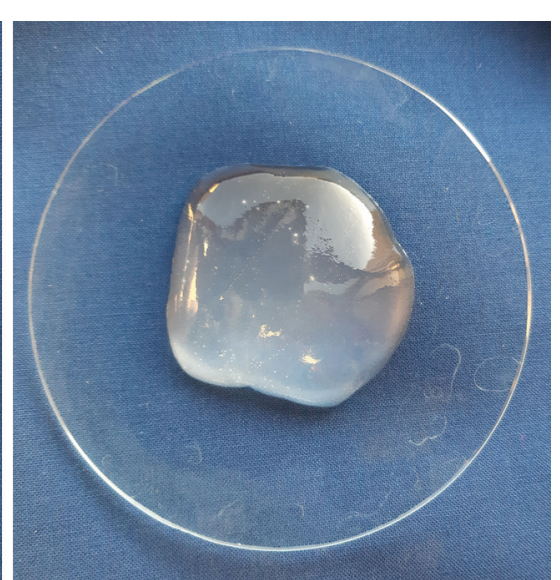

c)

Figure 4. a) Sclg-GG/b sample; b) the same sample cut in two pieces; c) the sample after the self-healing process. 
storage modulus $\left(G^{\prime} \approx \omega^{\mathrm{n}}\right)$ and loss modulus $\left(G^{\prime \prime} \approx \omega^{\mathrm{n}}\right)$ can be observed. Actually, at the critical gelation point, the moduli are expected to scale with frequency as $G^{\prime} \approx G^{\prime \prime} \approx \omega^{\mathrm{n}}$. This fact was evidenced for the first time by Chambon and Winter who generalized the scaling law of the two moduli with $0<n<1$. In our case, the average slope of the moduli is $n=0.37$. The estimated value of the critical exponent is rather low when compared to the first official theories: $n=$ 0.67 in the limit of Rouse dynamics (a model without hydrodynamic interactions) [58], $n=0.73$ for the percolation theory (using an analogy of gelation to resistor-superconductor networks) [59], $n=1$ for the mean field theory [60]. However, according to several experimental studies, it is now well stated that a universal value for $n$ that is dependent on parameters such as polymer concentration, molecular weight, or pre-gel history does not exist [26, 61-64]. Also, in previous studies carried out by the authors on GG chemically cross-linked with glutaraldehyde [28] (at different temperatures and with different amounts of glutaraldehyde), the critical exponents were always $<0.5$ while in the case of Locust Bean Gum/Xanthan [65] a value of $n=0.5$ was estimated.

From the observed $n$ value of 0.37 for the Sclg-GG sample, it is possible to estimate the fractal dimension $\left(d_{\mathrm{f}}\right)$ at the gel point, related to the connectivity properties of the incipient gel by applying the Muthukumar model [66], valid when the excluded volume effect is fully screened (reasonable assumption in the present work considering the final polymer concentration). The $d_{\mathrm{f}}$ of 2.16 estimated in this way indicates a network with low connectivity, as also evidenced by the low value of the storage modulus and the relatively high value of the loss tangent (see below).

If at the gel point the power-law $G^{\prime} \approx G^{\prime \prime} \approx \omega^{\mathrm{n}}$ holds in a sufficiently wide range of $\omega$, the loss tangent is given, according to the Kramers-Kronig relation, by $\tan \delta=\tan (n \pi / 2)$ [67]. In the present case, the phase difference between stress and strain, $\delta$ is approximately $33^{\circ}$ indicating a quite loose network with low elasticity, i.e., with a low degree of connectivity.

Furthermore, at the gel point, the storage modulus is higher than the loss modulus, as already reported for other physical gel [68-70]. This may be somehow related to specific polymer-polymer interactions leading to the formation of physical entanglements also supported by the fact that at least one of the two polymers is present with a concentration higher than the $c^{*}$ (overlapping concentration), $c^{*} \mathrm{Sclg} \approx 0.31 \%$ (unpublished results).

By adding borate ions, the reversible supramolecular assemblies already present in the system give a quite strong gel with the storage modulus one order of magnitude higher than the loss modulus. Furthermore, the shape of the mechanical spectra is similar to that exhibited by the pure GG/b system, with the loss modulus showing a minimum and a maximum value $v s . \omega$, indicating the presence of transient and labile linkages between the borax and GG chains. From Figure 2, looking at the values of $G^{\prime}$ and $G^{\prime \prime}$ at different $\omega$ values for $\mathrm{Sclg} / \mathrm{b}$ and $\mathrm{GG} / \mathrm{b}$ at $c_{\mathrm{p}}=0.35 \%$ and at those observed for the blend Sclg-GG/b at final $c_{\mathrm{p}}=0.7 \%$, the occurrence of a marked synergistic effect is well clear, while in the blend without borax no synergistic effect is detected.

This is a quite surprising result, considering the very different conformations that the polymers assume in aqueous media and the rather peculiar linkages occurring among the borate ions and the two polymer chains.

\subsection{Creep-recovery}

The creep-recovery curves were recorded, at $25^{\circ} \mathrm{C}$, for all the studied systems except for those showing solution behavior (GG $0.35 \%$ and GG $0.7 \%$ Sclg $0.35 \%)$. The stress $(\tau)$ imposed in the creep-recovery test spanned between 0.5 and $100 \mathrm{~Pa}$. In fact, while the characterization carried out in the linear viscoelastic field provides information about the structures of our systems, the creep-recovery tests in the non-linear field can provide useful information from a technological point of view. Figures $5 \mathrm{a}$ and $5 \mathrm{~b}$ show the trend of the compliance $J v s$. time t fixing $\tau=0.5 \mathrm{~Pa}$. Only in the case of Sclg-b $0.35 \%$ and Sclg-GG $0.7 \%$ samples (Figure $5 b$ ) the linear viscoelastic field was exceeded.

It is interesting to observe that the addition of borax had a significant impact on the creep-recovery behavior of all the examined systems. This is not only true for GG and Sclg systems at both concentrations $(0.35$ and $0.7 \%)$ but also for the blend Sclg-GG, whose maximum compliance falls down when borax is added. In order to evaluate the borax effect, a convenient approach consists in considering the recoverable strain $\gamma_{\text {RS }}$ (Equation (10)): 

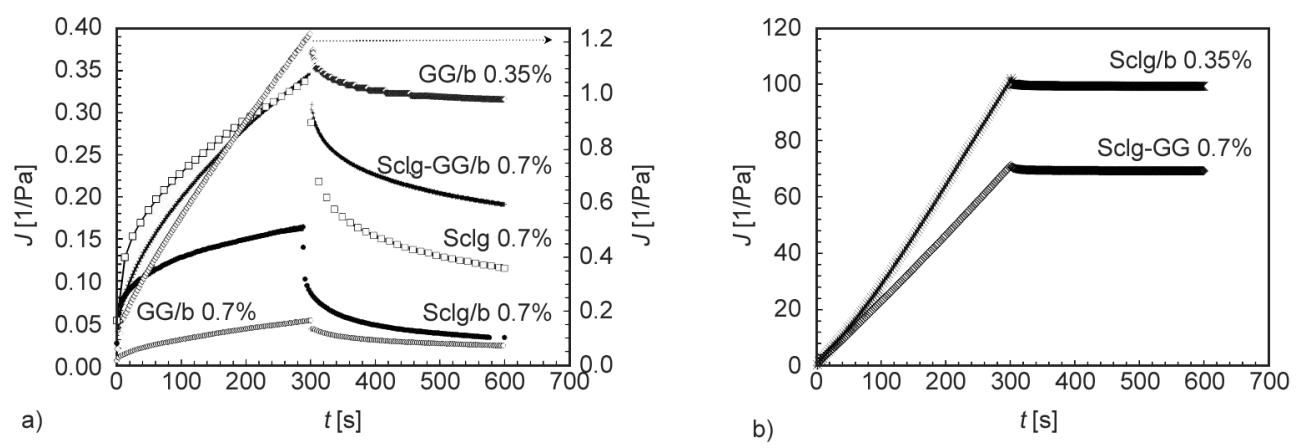

Figure 5. Creep-Recovery of the studied systems setting $\tau=0.5 \mathrm{~Pa}$. a) Systems falling in the linear viscoelastic field (maximum deformation does not exceed $\gamma_{c}-$ see Table 1). Continuous lines represent Equation (3) best fitting to the creep data. The arrow indicates the vertical axis pertaining to system GG/b $0.35 \%$. b) Systems exceeding the linear viscoelastic field. Sclg/b $0.35 \%$ falls in this category.

Table 3. Recoverable strain $\gamma_{\mathrm{RS}}$ deriving from creep-recovery tests (Figure 6).

\begin{tabular}{|l|c|c|c|c|c|c|c|}
\hline & Sclg/b 0.35\% & GG/b 0.35\% & Sclg 0.7\% & Sclg/b 0.7\% & GG/b 0.7\% & Sclg-GG 0.7\% & Sclg-GG/b 0.7\% \\
\hline$\gamma_{\text {RS }}[-]$ & 0.02 & 0.20 & 0.66 & 0.80 & 0.57 & 0.03 & 0.45 \\
\hline
\end{tabular}

$\gamma_{\mathrm{RS}}=\frac{\gamma_{\max }-\gamma_{\min }}{\gamma_{\max }}$

where $\gamma_{\max }$ is the maximum deformation of the sample (i.e., at the end of the creep phase, $300 \mathrm{~s}$ after applying the stress) and $\gamma_{\min }$ is the system deformation at the end of the recovery period (i.e., $300 \mathrm{~s}$ after the stress removal). The evaluated $\gamma_{\mathrm{RS}}$ values are reported in Table 3.

The recoverable strain increases by adding borax and by increasing polymer concentration. The synergistic effect of the Sclg-GG/b system compared to $\mathrm{Sclg} / \mathrm{b}$ and $\mathrm{GG} / \mathrm{b}$ samples are again evident. At $c_{\mathrm{p}}=0.35 \%$, only a few linkages are present for the formation of the network, and in both cases, a very low value of $\gamma_{\mathrm{RS}}$ is observed. The compliance of $\mathrm{Sclg} / \mathrm{b}$ is very high $\left(J \approx 100 \mathrm{~Pa}^{-1}\right)$, two orders of magnitude higher than that of GG/b $\left(J \approx 1 \mathrm{~Pa}^{-1}\right)$. Furthermore, the labile nature of $\mathrm{GG} /$ borax linkages results more effective for recovering the initial situation. An opposite behavior is evidenced when the polymer concentration increases to $0.7 \%$. The $\mathrm{Sclg} / \mathrm{b}$ system is now more efficient in the recovering process ( $\mathrm{Sclg} / \mathrm{b} 80 \%$ in comparison to $57 \%$ for $\mathrm{GG} / \mathrm{b}$ ) while the compliance is still higher $\left(J \approx 0.16 \mathrm{~Pa}^{-1}\right)$ than that of $\mathrm{GG} / \mathrm{b}$ $\left(J \approx 0.04 \mathrm{~Pa}^{-1}\right)$. When the two polymers are mixed together, the $\gamma_{\mathrm{RS}}$ is very low $(\approx 0.03)$ and the compliance very high $\left(J \approx 70 \mathrm{~Pa}^{-1}\right)$, indicating a very labile network (incipient gel point in the mechanical spectra). By adding the borax, an evident synergistic effect occurs as $\gamma_{\mathrm{RS}}$ increases up to 0.45 and $J$ decreases to $\approx 0.35 \mathrm{~Pa}^{-1}$. Network strength is responsible for the different fracture threshold of the two systems that is of the same order of magnitude of the critical stress evaluated from the stress sweep experiments (see Table 1).

It is now interesting comparing the linear viscoelastic properties of our systems deriving from creep tests and from frequency sweep tests, as reported in Figure 6, where the relaxation spectra calculated from the two different approaches are shown.

It can be noticed that, although differences exist between the frequency sweep (FS) and creep relaxation spectra, whatever the system considered, basically, they do not differ too much from each other, this proving the substantial coherence of the results obtained from the two experimental techniques. Indeed, not only do they substantially share the same number of Maxwell elements (2-3 plus an elastic element), but the existence of a linear correlation between the shear modulus deriving from the analysis of creep tests $\left(G_{\text {CREEP }}\right)$ and frequency sweep test $\left({ }_{\mathrm{G}}\right)$, supports this statement:

$G_{\text {CREEP }}=(0.93 \pm 0.18) \cdot G+(3.66 \pm 3.64) ; r=0.91$. In addition, as the slope of this correlation is not far from 1 and the intercept is small and statistically not far from zero, also in this case, we can approximately say the $G_{\text {CREEP }} \approx G$ for the studied systems.

One of the most evident differences existing between the FS and creep relaxation spectra consists in the shifting of FS spectra towards smaller relaxation times with respect to the analogous creep relaxation spectra. This finding, confirming what we previously found on similar systems [71], indicates that the frequency sweep test allows a better characterization of 

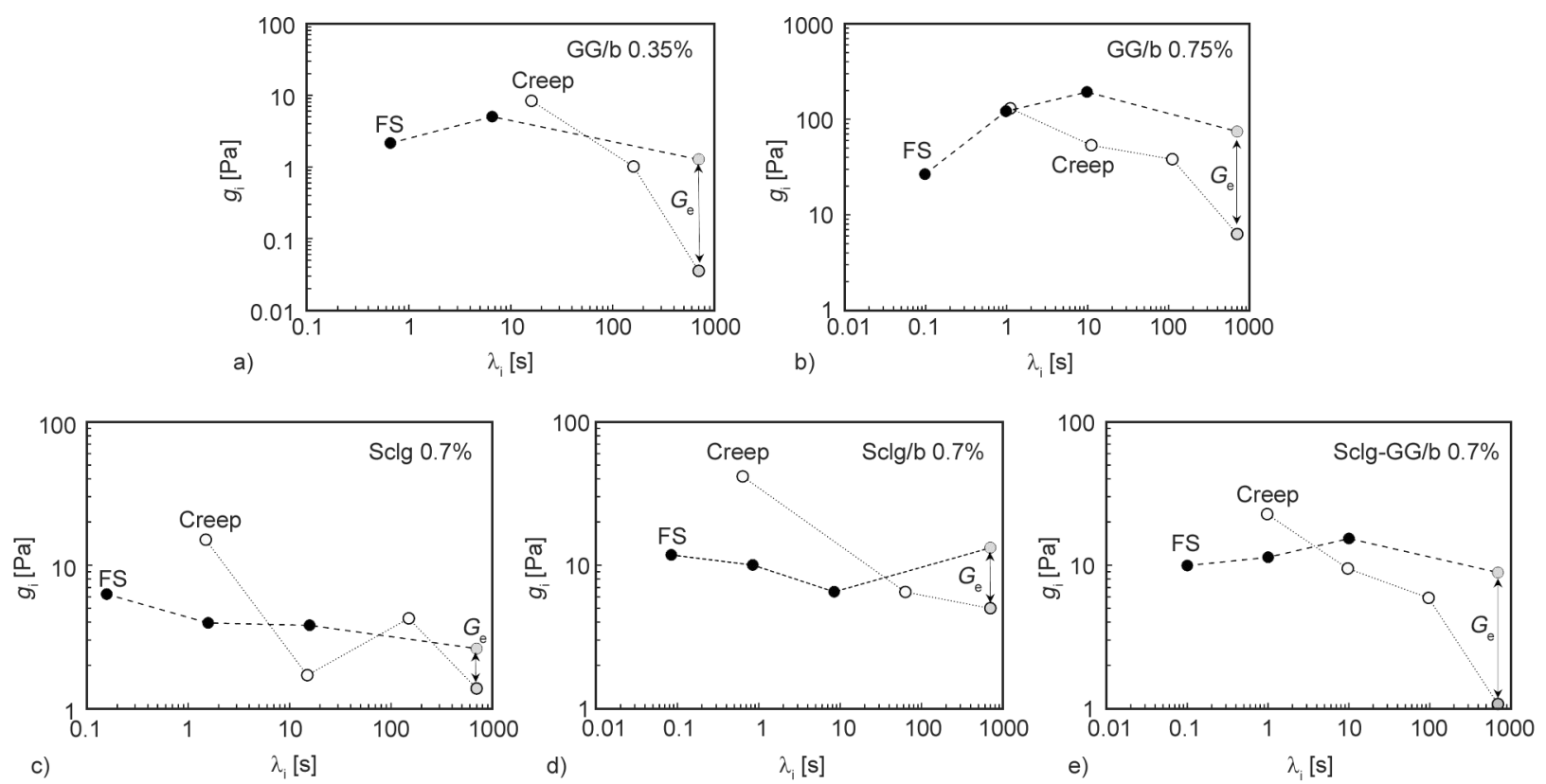

Figure 6. Comparison between the relaxation spectra, referring to the systems reported in Figure 5a, and determined by fitting the generalized Maxwell model to frequency sweep (FS, Equations (1) and (2); dashed line) and creep (Equation (3); dotted line) data. $g_{\mathrm{i}}$ and $\lambda_{\mathrm{i}}$ are, respectively, the elastic modulus and the relaxation time of the $i^{\text {th }} \mathrm{el}-$ ement of the generalized Maxwell model, while $G_{\mathrm{e}}$ (grey dots) is the modulus of the purely elastic element of the generalized Maxwell model arbitrarily depicted in correspondence of a relaxation time of $800 \mathrm{~s}$. a) GG/b $0.35 \%$ system, b) GG/b 0.75\% system, c) Sclg 0.7\% system, d) Sclg/b 0.7\% system, e) Sclg-GG/b 0.7\% system.

the smaller relaxation times associated with smaller characteristic lengths. The opposite takes place for the creep tests.

Finally, Figure 7 shows the time evolution of the compliance $J$ when the samples Sclg-GG $0.7 \%$ and Sclg-GG/b $0.7 \%$ undergo a stepwise sequence of increasing stress, each one followed by a recovery phase $(\tau=0)$. The remarkable difference of the two systems' behavior, due to the borax, is clearly evident. While Sclg-GG/b $0.7 \%$ can always recover part of the deformation, Sclg-GG $0.7 \%$ does not show

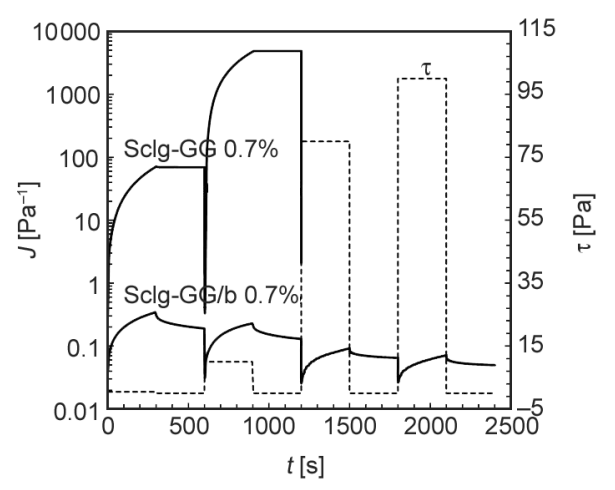

Figure 7. Compliance $J$ time evolution (solid lines) when increasing stepwise stress $(\tau)$ procedure (see dashed line), intercalated by an equal duration recovery phase, is applied to Sclg-GG $0.7 \%$ and SclgGG/b $0.7 \%$ systems. any recovery, and when $\tau$ exceeds $6 \mathrm{~Pa}$, the deformation becomes too wide to be recorded.

\subsection{Low field NMR characterization}

It is well known that the magnetic relaxation of hydrogen atoms in pure water depends on temperature and the intensity of the applied magnetic field. However, when solubilized or dispersed substances (such as polymeric chains) are present inside water, as it happens in the case of solutions, suspensions, and gels, hydrogen relaxation is also heavily affected by the ratio between the substances/water interfacial surface $(S)$ and the water volume $(V)$ [41] (Equation (11)):

$$
\left(\frac{1}{T_{2}}\right)_{\mathrm{m}}=\frac{1}{T_{2 \mathrm{H}_{2} \mathrm{O}}}+\frac{S}{V} \frac{a}{T_{2 \mathrm{~s}}}
$$

where $\left(1 / T_{2}\right)_{\mathrm{m}}$ is the average inverse relaxation time, $T_{2 \mathrm{H}_{2} \mathrm{O}}$ is the water hydrogen atoms relaxation in pure water (absence of solubilized/dispersed substances - free water relaxation time), $a$ is the thickness of the water layer surrounding the solubilized/dispersed substances (bound water), where hydrogen relaxation is reduced as surface behaves as a magnetization absorber. Finally, $T_{2 \mathrm{~s}}$ is the relaxation time of the hydrogen atoms belonging to the bound water. 
This is the reason why LF-NMR is a useful technique to study the three-dimensional organization of solubilized/dispersed substances in hydrogenated liquids $[72,73]$. Indeed, not only the sol-gel transition can imply a consistent rearrangement of the polymeric chains [74], but also the final three-dimensional chains disposition, the gel fingerprint, can heavily affect the $S / V$ ratio, this is reflecting in a variation of $\left(1 / T_{2}\right)_{\mathrm{m}}$ and $T_{2 \mathrm{~m}}$ (Equation (11)) as $a$ and $T_{2 \mathrm{~s}}$ do not depend on $S / V[40,41]$.

Table 4 enables indirectly evaluating the $S / V$ variation upon $c_{\mathrm{p}}$ increase and crosslinker (borax) addition via the determination of $T_{2 \mathrm{~m}}$ (although $\left(1 / T_{2}\right)_{\mathrm{m}} \neq$ $1 / T_{2 \mathrm{~m}}$, it is easy to experimentally verify that $T_{2 \mathrm{~m}}$ is inversely proportional to $\left.\left(1 / T_{2}\right)_{\mathrm{m}}\right)$. Indeed, in the case of the individual components, Sclg and GG, $T_{2 \mathrm{~m}}$ decrease with $c_{\mathrm{p}}$ (from 0.35 to $0.7 \%$ ) reflect the increase of the $S / V$ ratio: the higher the polymer content, the higher the contact surface. The fact that only one relaxation time $\left(T_{2 \mathrm{~m}}=T_{21}\right)$ characterizes the relaxation of Sclg and GG based samples indicates that their threedimensional networks are homogeneous, i.e., all the hydrogen atoms experience the same local condition, this reflecting in a similar spatial organization of the polymeric network (in this sense, water hydrogen can be seen as the probe of the LFNMR). Noticeably, whatever the explored $c_{\mathrm{p}}$, Sclg is characterized by a lower $T_{2 \mathrm{~m}}$ in comparison to those estimated for GG samples. This could be due to the high value of Sclg triple helices persistence length that has to be compared with the persistence length of the flexible GG chains, assuming a coil conformation. This translates, for Sclg samples, into a greater surface available for the interaction between the polymeric chains and water molecules, i.e., a lower $T_{2 \mathrm{~m}}$. The addition of borax, whatever $c_{\mathrm{p}}$ and polymer (Sclg or GG), results in a reduction of $T_{2 \mathrm{~m}}$ that can be interpreted as an increase of $S / V$. However, while in the case of Sclg $T_{2 \mathrm{~m}}$ decrease is huge $\left(T_{2 \mathrm{~m}}\right.$ becomes about one third $\left(c_{\mathrm{p}}=0.35 \%\right)$ and one fifth $\left(c_{\mathrm{p}}=0.7 \%\right)$ of its value in the absence of borax - Table 4), in the GG case, $T_{2 \mathrm{~m}}$ decrease is smaller, especially when $c_{\mathrm{p}}=0.35 \%$. Again, this reflects the different variations of $S / V$ induced by borax. When the mixed system (Sclg-GG) is considered, the addition of borax not only implies a considerable reduction of $T_{2 \mathrm{~m}}$ but it induces the transition from a homogenous polymeric architecture characterized by only one relaxation time to more complex, heterogeneous chain organizations characterized by two relaxation times. In the light of the relation existing between the relaxation time $\left(T_{2 \mathrm{i}}\right)$ and the mesh size $\left(\xi_{\mathrm{i}}\right)$ (Equation (8)), this means that borax addition causes the formation of big and small meshes in the proportion 24:76 (see Table 4). It is possible to go further in the characterization of the polymeric networks by determining the continuos mesh size distribution, relying on Equation (8) and the average mesh size $(\xi)$ obtained from the rheological characterization (see Table 2). Concerning this aspect, Figure 8 shows the continuous mesh size distribution referring to SclgGG $0.7 \%$ and Sclg-GG/b $0.7 \%$. As the Sclg-GG $0.7 \%$ system represents the transition from a solution to a gel, as evidenced by the mechanical spectrum (see Figure 2e), the corresponding mesh size distribution needs some comments. While mesh sizes up to $\approx 300 \mathrm{~nm}$ are realistic [43], higher values are not probable. Actually, bigger meshes are somehow artificial, and they simply represent the relaxation of water molecules that are not trapped inside real

Table 4. Average relaxation times, $T_{2 \mathrm{~m}}$, decay time constants $\left(T_{2 \mathrm{i}}\right)$, mesh size $\xi_{\mathrm{i}}$ and weight $\%\left(A_{\mathrm{i} \%}\right)$ referring to all the investigated samples, at $25^{\circ} \mathrm{C}$.

\begin{tabular}{|l|r|r|c|c|c|c|c|}
\hline \multicolumn{1}{|c|}{ Sample } & $\begin{array}{r}\boldsymbol{T}_{\mathbf{2 m}} \\
{[\mathbf{m s}]}\end{array}$ & $\begin{array}{c}\boldsymbol{T}_{\mathbf{2 1}} \\
{[\mathbf{m s}]}\end{array}$ & $\begin{array}{c}\boldsymbol{\xi}_{\mathbf{1}} \\
{[\mathbf{n m}]}\end{array}$ & $\boldsymbol{A}_{\mathbf{1} \%}$ & $\begin{array}{c}\boldsymbol{T}_{\mathbf{2 2}} \\
{[\mathbf{m s}]}\end{array}$ & $\begin{array}{c}\boldsymbol{\xi}_{\mathbf{2}} \\
{[\mathbf{n m}]}\end{array}$ & $\boldsymbol{A}_{\mathbf{2}}$ \\
\hline $\mathrm{H}_{2} \mathrm{O}$ & 3007 & 3007 & & 100 & - & - & - \\
\hline $\mathrm{Sclg} 0.7 \%$ & 1501 & 1501 & 78.0 & 100 & - & - & - \\
\hline $\mathrm{Sclg} / \mathrm{b} 0.7 \%$ & 305 & 305 & 57.4 & 100 & - & - & - \\
\hline $\mathrm{Sclg} 0.35 \%$ & 1584 & 1584 & 125.0 & 100 & - & - & - \\
\hline $\mathrm{Sclg} / \mathrm{b} 0.35 \%$ & 467 & 467 & 106.0 & 100 & - & - & - \\
\hline GG 0.7\% & 2075 & 2075 & - & 100 & - & - & - \\
\hline GG/b 0.7\% & 878 & 941 & 14.2 & 85 & 514 & 31.3 & 15 \\
\hline GG 0.35\% & 2523 & 2523 & - & 100 & - & - & - \\
\hline GG/b 0.35\% & 2180 & 2180 & 97.5 & 100 & - & - & - \\
\hline Sclg-GG 0.7\% & 1891 & 1891 & 158.0 & 100 & - & - & - \\
\hline Sclg-GG/b 0.7\% & 544 & 733 & 85.4 & 24 & 485 & 51.0 & 76 \\
\hline
\end{tabular}




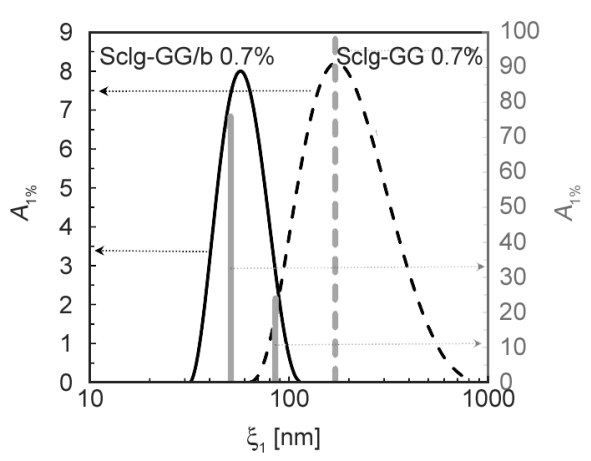

Figure 8. Continuous mesh size distribution referring to Sclg-GG 0.7\% (dashed line) and Sclg-GG/b 0.7\% (continuous line). Dashed and solid vertical lines indicate, respectively, the discrete mesh size distribution reported in Table 4 and referring to SclgGG $0.7 \%$ and Sclg-GG/b 0.7\%.

meshes but depict the sol phase present in the system. However, it is important to show the mesh size distribution of the Sclg-GG 0.7\% sample because this allows a better understanding of the effect of borax on the system's internal structure. It is also evident from Figure 8 that borax addition does not significantly alter the shape of the mesh size distribution while it induces a noticeable reduction of the mesh sizes that span from 20 to $150 \mathrm{~nm}$. It has to be underlined that this kind of information is of paramount importance in the case of polymeric-controlled delivery systems when release kinetics is essentially ruled by drug diffusion through the polymeric network meshes.

Indeed, it is well known that the drug diffusion coefficient is strongly dependent on the mesh size distribution [75]. Finally, taking into account the relation between $\xi$ and the radius, $R_{\mathrm{f}}$, of the polymeric fibers/chains (assumed to be long cylinders) in the case of a cubical network organization [76, 42] (Equation (12)):

$$
\xi=R_{\mathrm{f}} \sqrt{3 \pi \frac{1-0,58 \varphi}{\varphi}}
$$

$\varphi$ is the polymeric chains volume fraction $\approx 4.5 \cdot 10^{-2}$, we can estimate, in the case of Sclg-GG/b $0.7 \%$, a value of $R_{\mathrm{f}} \approx 1.3 \mathrm{~nm}$, which is compatible with the radius of the Sclg triplex helix cross-section [77].

\section{Conclusions}

For the first time, the effect of borax on a mixed system of Sclg and GG was considered.

As previously evidenced [30], each single polysaccharide, GG and Sclg, is capable of giving gels in the presence of borax, and the tablets obtained by compression of the freeze-dried hydrogels show a similar anisotropic swelling in water.

In the water uptake experiments, the anisotropic force applied during compression and the presence of the borax linkages induce the tablets of $\mathrm{Sclg} / \mathrm{b}$ and GG/b to swell preferentially along one direction. This peculiarity, also shown by the Sclg-GG mixed system, is very interesting. In fact, provided that borax is capable of inducing a highly ordered configuration of parallel aligned bundles of Sclg and GG chains, the newly reported results on the one-direction dimension increases of swelled tablets (see Figure 1) indicate that also a mixture of the two polymers leads to the formation of a three-dimensional network capable of giving an anisotropic swelling. This evidence has different implications:

I) when preparing a Sclg-GG mixture, a phase separation does not occur, but a homogeneous system is obtained; II) the entanglements of Sclg and GG chains are immobilized by the borax linkages leading to microscopic ordered domains (based on both kinds of chains) that undergo an anisotropic elongation when the freeze-dried samples are compressed along one direction.

The rheological characterization of each polymer (with and without borax) shows two completely different mechanical spectra (Figure 2). However, when the two polymers are mixed together, different mechanical spectra are recorded, indicating a noticeable synergistic effect.

As far as the mesh size is concerned, the GG/b ( $c_{\mathrm{p}}=$ $0.7 \%$ ) sample shows a $\xi$ value of $\approx 27 \mathrm{~nm}$ while $\mathrm{Sclg} / \mathrm{b}\left(c_{\mathrm{p}}=0.7 \%\right)$ shows a more than double value $(\xi \approx 57 \mathrm{~nm})$, indicating that the network is much more loose. At lower $c_{\mathrm{p}}(0.35 \%)$, the difference is less evident, but anyhow the GG/b system always has a network tighter $(\xi \approx 98 \mathrm{~nm})$ than that of $\mathrm{Sclg} / \mathrm{b}$ $(\xi \approx 106 \mathrm{~nm})$. In the case of Sclg-GG/b, a synergistic effect takes place since the $\xi$ value $(\approx 56 \mathrm{~nm})$ is much lower than those of every single system $(\mathrm{Sclg} / \mathrm{b}$ $\approx 106 \mathrm{~nm} ; \mathrm{GG} / \mathrm{b} \approx 98 \mathrm{~nm}$ ).

The gel-point, evidenced in the mechanical spectra of the Sclg-GG sample (Figure 2e), indicates that the Sclg and GG chains are already entangled in the absence of the crosslinker, thus forming an incipient gel. By adding borax, the loose and reversible supramolecular assemblies are temporarily fixed, leading to a gel with an evident elastic character. The power law observed at the gel point implies a self-similar 
structure of the network, whose connectivity is related to the $d_{\mathrm{f}}$ (network fractal dimension). The $\tan \delta$ and the $d_{\mathrm{f}}$ values indicate a loose network, as confirmed by the estimated very high $\xi$ value $(\approx 158 \mathrm{~nm})$. It should be underlined that the fractal dimension is directly related to the mesh size of the network, whose dimensions deeply influence the performances of the hydrogels if used for food and/or biomedical applications. In this sense, also the self-healing properties, shown by the mixed system, could be an important factor, as evidenced by other self-healing polysaccharide-based systems, where borax was used to form dynamic bonds that found significant applications also in tissue engineering, soft robotics and $3 \mathrm{D}$ printing $[78,79]$.

The creep experiments, carried out in the linear viscoelastic regime, essentially confirm what was found by means of oscillatory tests.

The combined use of rheology and LF-NMR provides a deeper insight into the characterization of the new Sclg-GG/borax hydrogel, a system that could also be considered suitable for the formulation of modified drug delivery dosage forms for human tissue repair, wound dressing, as well as for applications in food staff and cosmetic products.

\section{Acknowledgements}

Financial supports from Società Italiana di Reologia - SIR Italy, by Fondazione Cassa di Risparmio di Trieste, Italy (\# 10.3069), by the so-called 'Programma di valorizzazione dei brevetti del sistema universitario del Friuli Venezia Giulia' - Unity FVG PoC, 2020, Italy and by Sapienza University of Rome, 'Progetto di Ricerca RM120172AE742B3B' are acknowledged.

\section{References}

[1] Norisuye T., Yanaki T., Fujita H.: Triple helix of a Schizophyllum commune polysaccharide in aqueous solution. Journal of Polymer Science: Polymer Physics Edition, 18, 547-558 (1980). https://doi.org/10.1002/pol.1980.180180314

[2] Yanaki T., Norisuye T., Fujita H.: Triple helix of Schizophyllum commune polysaccharide in dilute solution. 3 . Hydrodynamic properties in water. Macromolecules, 13, 1462-1466 (1980). https://doi.org/10.1021/ma60078a019

[3] Giavasis I., Harvey L. M., McNeil B.: Scleroglucan. in 'Biopolymers, polysaccharides II' (eds.: Steinbüchel A., Vandamme E. J., De Baets S.) Wiley, Weinheim, 37-60 (2002).
[4] Rizk S., Duru C., Gaudy D., Jacob M., Ferrari F., Bertoni M., Caramella C.: Physico-chemical characterization and tabletting properties of scleroglucan. International Journal of Pharmaceutics, 112, 125-131 (1994). https://doi.org/10.1016/0378-5173(94)90422-7

[5] Coviello T., Palleshi A., Grassi M., Matricardi P., Bocchinfuso G., Alhaique F.: Scleroglucan: A versatile polysaccharide for modified drug delivery. Molecules, 10, 6-33 (2005).

https://doi.org/10.3390/10010006

[6] Romanelli L., Alhaique F., Riccieri F. M., Santucci E., Valeri P.: Investigation of the features of scleroglucan, a polysaccharide of fungin origin, as a vehicle for ocular topical administration. Pharmacological Research, 27, 127-128 (1993).

https://doi.org/10.1006/phrs.1993.1098

[7] Maier H., Anderson M., Karl C., Magnuson K., Whistler R. L.: Guar, locust bean gum, tara, and fenugreek gums. in 'Industrial gums: Polysaccharides and their derivatives' (eds.: Whistler R. L., BeMiller J. N.) Academic Press, New York, 181-226 (1993).

[8] McCleary B. V., Clark A. H., Dea I. C. M., Rees D. A.: The fine structures of carob and guar galactomannans. Carbohydrate Research, 139, 237-260 (1985).

https://doi.org/10.1016/0008-6215(85)90024-2

[9] Fox J. E.: Seed gums. in 'Thickening and gelling agents for food' (ed.: Imeson A.) Blackie Academic Professional, New York, 262-283 (1997).

[10] Kucera C. H., DeMott D. N.: Drilling fluid containing crosslinked polysaccharide derivative. U.S. Patent 4257903, USA (1981).

[11] Brode G. L., Goddard E. D., Harris W. C., Salensky G. A.: Cationic polysaccharides for cosmetics and therapeutics. in 'Cosmetic and pharmaceutical applications of polymers' (eds.: Gebelein C. G., Cheng T. C., Yang V. C.) Plenum Press, New York, 117-128 (1991).

[12] Picout D. R., Ross-Murphy S. B.: On the Mark-Houwink parameters for galactomannans. Carbohydrate Polymers, 70, 145-148 (2007).

https://doi.org/10.1016/j.carbpol.2007.03.010

[13] Vijayendran B. R., Bone T.: Absolute molecular weight and molecular weight distribution of guar by size exclusion chromatography and low-angle laser light scattering. Carbohydrate Polymers, 4, 299-313 (1984). https://doi.org/10.1016/0144-8617(84)90005-5

[14] Gliko-Kabir I., Yagen B., Penasi A., Rubinstein A.: Low swelling, crosslinked guar and its potential use as colonspecific drug carrier. Pharmaceutical Research, 15, 1019-1025 (1998).

https://doi.org/10.1023/A:1011921925745

[15] Coviello T., Alhaique F., Dorigo A., Matricardi P., Grassi M.: Two galactomannans and scleroglucan as matrices for drug delivery: Preparation and release studies. European Journal of Pharmaceutics and Biopharmaceutics, 66, 200-209 (2007).

https://doi.org/10.1016/j.ejpb.2006.10.024 
[16] Pezron E., Leibler L., Lafuma F.: Complex formation in polymer-ion solutions. 2. Polyelectrolyte effects. Macromolecules, 22, 2656-2662 (1989).

https://doi.org/10.1021/ma00196a021

[17] Shibayama M., Yoshizawa H., Kurokawa H., Fujiwara H., Nomura S.: Sol-gel transition of poly(vinyl alcohol)-borate complex. Polymer, 29, 2066-2071 (1988). https://doi.org/10.1016/0032-3861(88)90182-6

[18] Bocchinfuso G., Palleschi A., Mazzuca C., Coviello T., Alhaique F., Marletta G.: Theoretical and experimental study on a self-assembling polysaccharide forming nanochannels: Static and dynamic effects induced by a soft confinement. The Journal of Physical Chemistry B, 112, 6473-6483 (2008). https://doi.org/10.1021/jp076074f

[19] Palleschi A., Coviello T., Bocchinfuso G., Alhaique F.: Investigation on a new scleroglucan/borax hydrogel: Structure and drug release. International Journal of Pharmaceutics, 322, 13-21 (2006).

https://doi.org/10.1016/j.ijpharm.2006.05.029

[20] Kesavan S., Prud'homme R. K.: Rheology of guar and (hydroxypropyl) guar crosslinked by borate. Macromolecules, 25, 2026-2032 (1992).

https://doi.org/10.1021/ma00033a029

[21] Tayal A., Pai V. B., Khan S. A.: Rheology and microstructural changes during enzymatic degradation of a guar-borax hydrogel. Macromolecules, 32, 5567-5574 (1999). https://doi.org/10.1021/ma990167g

[22] Pezron E., Leibler L., Ricard A., Audebert R.: Reversible gel formation induced by ion complexation. 2. Phase diagrams. Macromolecules, 21, 1126-1131 (1988). https://doi.org/10.1021/ma00182a046

[23] Pezron E., Ricard A., Lafuma F., Audebert R.: Reversible gel formation induced by ion complexation. 1. Boraxgalactomannan interactions. Macromolecules, 21, 11211125 (1988). https://doi.org/10.1021/ma00182a045

[24] Pezron E., Leibler L., Ricard A., Lafuma F., Audebert R.: Complex formation in polymer-ion solution. 1. Polymer concentration effects. Macromolecules, 22, 1169-1174 (1989). https://doi.org/10.1021/ma00193a030

[25] Fang Y., Takahashi R., Nishinari K.: A gel network constituted by rigid schizophyllan chains and nonpermanent cross-links. Biomacromolecules, 5, 126-136 (2004). https://doi.org/10.1021/bm034261n

[26] Grisel M., Muller G.: Rheological properties of the schizophyllan-borax system. Macromolecules, 31, 4277-4281 (1998). https://doi.org/10.1021/ma970485k

[27] Bluhm L. T., Deslandes Y., Marchessault R. H., Pérez S., Rinaudo M.: Solid-state and solution conformation of scleroglucan. Carbohydrate Research, 100, 117-130 (1982).

https://doi.org/10.1016/S0008-6215(00)81030-7
[28] Sandolo C., Matricardi P., Alhaique F., Coviello T.: Effect of temperature and cross-linking density on rheology of chemical cross-linked guar gum at the gel point. Food Hydrocolloids, 23, 210-220 (2009). https://doi.org/10.1016/j.foodhyd.2008.01.001

[29] Pezron E., Ricard A., Leibler L.: Rheology of galactomannan-borax gels. Journal of Polymer Science Part B: Polymer Physics, 28, 2445-2461 (1990).

https://doi.org/10.1002/polb.1990.090281301

[30] Bocchinfuso G., Mazzuca C., Sandolo C., Margheritelli S., Alhaique F., Coviello T., Palleschi A.: Guar gum and scleroglucan interactions with borax: Experimental and theoretical studies of an unexpected similarity. The Journal of Physical Chemistry B, 114, 13059-13068 (2010).

https://doi.org/10.1021/jp105838t

[31] Kök M. S., Hill S. E., Mitchell J. R.: Viscosity of galactomannans during high temperature processing: Influence of degradation and solubilisation. Food Hydrocolloids, 13, 535-542 (1999).

https://doi.org/10.1016/S0268-005X(99)00040-5

[32] De’Nobili M. D., Rojas A. M., Abrami M., Lapasin R., Grassi M.: Structure characterization by means of rheological and NMR experiments as a first necessary approach to study the L-(+)-ascorbic acid diffusion from pectin and pectin/alginate films to agar hydrogels that mimic food materials. Journal of Food Engineering, 165, 82-92 (2015).

https://doi.org/10.1016/j.jfoodeng.2015.05.014

[33] Kuijpers A. J., Engbers G. H. M., Feijen J., De Smedt S. C., Meyvis T. K. L., Demeester J., Krijgsveld J., Zaat S. A. J., Dankert J.: Characterization of the network structure of carbodiimide cross-linked gelatin gels. Macromolecules, 32, 3325-3334 (1999).

https://doi.org/10.1021/ma981929v

[34] Draper N. R., Smith H.: Applied regression analysis. Wiley, New York (1966).

[35] Abrami M., Marizza P., Zecchin F., Bertoncin P., Marson D., Lapasin R., de Riso F., Posocco P., Grassi G., Grassi M.: Theoretical importance of PVP-alginate hydrogels structure on drug release kinetics. Gels, 5, 22 (2019). https://doi.org/10.3390/gels5020022

[36] Pasut E., Toffanin R., Voinovich D., Pedersini C., Murano E., Grassi M.: Mechanical and diffusive properties of homogeneous alginate gels in form of particles and cylinders. Journal of Biomedical Materials Research Part A, 87, 808-818 (2008).

https://doi.org/10.1002/jbm.a.31680

[37] Flory P. J.: The thermodynamics of polymer solutions. in 'Principles of polymer chemistry' Cornell University Press, Ithaca, 469-470 (1953).

[38] Schurz J.: Rheology of polymer solutions of the network type. Progress in Polymer Science, 16, 1-53 (1991). https://doi.org/10.1016/0079-6700(91)90006-7

[39] Meiboom S., Gill D.: Modified spin-echo method for measuring nuclear relaxation times. Review of Scientific Instruments, 29, 688-691 (1958).

https://doi.org/10.1063/1.1716296 
[40] Brownstein K. R., Tarr C. E.: Importance of classical diffusion in NMR studies of water in biological cells. Physical Review A, 19, 2446-2453 (1979). https://doi.org/10.1103/PhysRevA.19.2446

[41] Chui M. M., Phillips R. J., McCarthy M. J.: Measurement of the porous microstructure of hydrogels by nuclear magnetic resonance. Journal of Colloid and Interface Science, 174, 336-344 (1995). https://doi.org/10.1006/jcis.1995.1399

[42] Abrami M., Chiarappa G., Farra R., Grassi G., Marizza P., Grassi M.: Use of low-field NMR for the characterization of gels and biological tissues. ADMET \& DMPK, 6, 34-46 (2018). https://doi.org/10.5599/admet.6.1.430

[43] Coviello T., Matricardi P., Alhaique F., Farra R., Tesei G., Fiorentino S., Asaro F., Milcovich G., Grassi M.: Guar gum/borax hydrogel: Rheological, low field NMR and release characterizations. Express Polymer Letters, 7, 733-746 (2013).

https://doi.org/10.3144/expresspolymlett.2013.71

[44] Whittal K. P., MacKay A. L.: Quantitative interpretation of NMR relaxation data. Journal of Magnetic Resonance, 84, 134-152 (1989).

https://doi.org/10.1016/0022-2364(89)90011-5

[45] Provencher S. W. A.: A constrained regularization method for inverting data represented by linear algebraic or integral equations. Computer Physics Communications, 27, 213-227 (1982). https://doi.org/10.1016/0010-4655(82)90173-4

[46] Wang X., Ni Q.: Determination of cortical bone porosity and pore size distribution using a low field pulsed NMR approach. Journal of Orthopedic Research, 21, 312-319 (2003).

https://doi.org/10.1016/S0736-0266(02)00157-2

[47] Masuda T., Kitagawa K., Inoue T., Onogi S.: Rheological properties of anionic polystyrenes. II. Dynamic viscoelasticity of blends of narrow-distribution polystyrenes. Macromolecules, 3, 116-125 (1970). https://doi.org/10.1021/ma60014a002

[48] Osaki K., Nishimura Y., Kurata M.: Viscoelastic properties of semidilute polystyrene solutions. Macromolecules, 18, 1153-1157 (1985).

https://doi.org/10.1021/ma00148a019

[49] Ferry J. D., Landel R. F., Williams M. L.: Extensions of the rouse theory of viscoelastic properties to undiluted linear polymers. Journal of Applied Phisycs, 26, 359-362 (1955).

https://doi.org/10.1063/1.1721997

[50] Chompff A. J., Prins W.: Viscoelasticity of networks consisting of crosslinked or entangled macromolecules. II. Verification of the theory for entanglement networks. The Journal of Chemical Phisycs, 48, 235-243 (1968). https://doi.org/10.1063/1.1667909

[51] Lin H-L., Yu T-L., Cheng C-H.: Reentrant behavior of poly(vinyl alcohol)-borax semidilute aqueous solutions. Colloid and Polymer Science, 278, 187-194 (2000). https://doi.org/10.1007/s003960050031
[52] Gao S., Guo J., Nishinari K.:Thermoreversible konjac glucomannan gel crosslinked by borax. Carbohydrate Polymers, 72, 315-325 (2008).

https://doi.org/10.1016/j.carbpol.2007.08.015

[53] Cates M. E.: Reptation of living polymers: Dynamics of entangled polymers in the presence of reversible chain-scission reactions. Macromolecules, 20, 22892296 (1987).

https://doi.org/10.1021/ma00175a038

[54] de Gennes P. G.: Reptation of a polymer chain in the presence of fixed obstacles. The Journal of Chemical Physics, 55, 572-579 (1971).

https://doi.org/10.1063/1.1675789

[55] Koike A., Nemoto N., Inoue T., Osaki K.: Dynamic light scattering and dynamic viscoelasticity of poly(vinyl alcohol) in aqueous borax solutions. 1. Concentration effect. Macromolecules, 28, 2339-2344 (1995).

https://doi.org/10.1021/ma00111a029

[56] Beltman H., Lyklema J.: Rheological monitoring of the formation of polyvinyl alcohol-Congo red gels. Faraday Discussions of the Chemical Society, 57, 92-100 (1974). https://doi.org/10.1039/DC9745700092

[57] Allain C., Salome L.: Sol-gel transition of hydrolyzed polyacrylamide + chromium(III): Rheological behavior versus crosslink concentration. Macromolecules, 20, 2957-2958 (1987).

https://doi.org/10.1021/ma00177a056

[58] Martin J. E., Adolf D., Wilcoxon J. P.: Viscoelasticity near the sol-gel transition. Physical Review A, 39, 1325-1332 (1989).

https://doi.org/10.1103/PhysRevA.39.1325

[59] Stauffer D., Coniglio A., Adam M.: Gelation and critical phenomena. Advances in Polymer Science, 44, 103158 (1982).

https://doi.org/10.1007/3-540-11471-8 4

[60] Martin J. E., Adolf D.: The sol-gel transition in chemical gels. Annual Review of Physical Chemistry, 42, 311-339 (1991).

https://doi.org/10.1146/annurev.pc.42.100191.001523

[61] Coviello T., Burchard W.: Criteria for the point of gelation in reversibly gelling systems according to dynamic light scattering and oscillatory rheology. Macromolecules, 25, 1011-1012 (1992).

https://doi.org/10.1021/ma00028a082

[62] Hsu S-H., Jamieson M.: Viscoelastic behaviour at the thermal sol-gel transition of gelatin. Polymer, 34, 26022608 (1993).

https://doi.org/10.1016/0032-3861(93)90596-3

[63] Matricardi P., Dentini M., Crescenzi V., Ross-Murphy S. B.: Gelation of chemically cross-linked polygalacturonic acid derivatives. Carbohydrate Polymers, 7, 215-220 (1995).

https://doi.org/10.1016/0144-8617(95)00055-C 
[64] Richter S., Boyko V., Schrtöter K.: Gelation studies on a radical chain cross-linking copolymerization process: Comparison of the critical exponents obtained by dynamic light scattering and rheology. Macromolecular Rapid Communications, 25, 542-546 (2004). https://doi.org/10.1002/marc.200300209

[65] Sandolo C., Bulone D., Mangione M., Margheritelli S., Di Meo C., Alhaique F., Matricardi P., Coviello T.: Synergistic interaction of locust bean gum and xanthan investigated by rheology and light scattering. Carbohydrate Polymers, 82, 733-741 (2010). https://doi.org/10.1016/j.carbpol.2010.05.044

[66] Muthukumar M.: Screening effect on viscoelasticity near the gel point. Macromolecules, 22, 4656-4658 (1989).

https://doi.org/10.1021/ma00202a050

[67] Ferry J. D.: Viscoelastic properties of polymers. Wiley, New York (1980).

[68] Clark A. H., Ross-Murphy S. B.: Structural and mechanical properties of biopolymer gels. Advances in Polymer Science, 83, 57-192 (1987).

https://doi.org/10.1007/BFb0023332

[69] Hossain K. S., Miyanaga K., Maeda H., Nemoto N.: Sol-gel transition behavior of pure l-carrageenan in both salt-free and added salt states. Biomacromolecules, 2, 442-449 (2001).

https://doi.org/10.1021/bm000117f

[70] Nystrom B., Walderhaug H., Hansen F. K., Lindman B.: Rheological behavior during thermoreversible gelation of aqueous mixtures of ethyl(hydroxyethyl)cellulose and surfactants. Langmuir, 11, 750-757 (1995).

https://doi.org/10.1021/la00003a014

[71] Coviello T., Margheritelli S., Matricardi P., Di Meo C., Cerreto F., Alhaique F., Abrami M., Grassi M.: Influence of borate amount on the swelling and rheological properties of the scleroglucan/borax system. Journal of Applied Polymer Science, 133, 42860 (2016). https://doi.org/10.1002/app. 42860

[72] Cappelli A., Galeazzi S., Giuliani G., Anzini M., Grassi M., Lapasin R., Grassi G., Farra R., Dapas B., Aggravi M., Donati A., Zetta L., Boccia A. C., Bertini F., Samperi F., Vomero S.: Synthesis and spontaneous polymerization of oligo(ethylene glycol)-conjugated benzofulvene macromonomers. A polymer brush forming a physical hydrogel. Macromolecules, 42, 2368-2378 (2009).

https://doi.org/10.1021/ma802429g
[73] Lapasin R., Grassi M., Abrami M., Šebenik U.: Structural evolution of salt-free aqueous Laponite dispersions: A study based on low-field NMR relaxometry and rheological investigations. Colloids and Surfaces A Physicochemical and Engineering Aspects, 602, 125126 (2020).

https://doi.org/10.1016/j.colsurfa.2020.125126

[74] Abrami M., Siviello C., Grassi G., Larobina D., Grassi M.: Investigation on the thermal gelation of chitosan/ $\beta$ glycerophosphate solutions. Carbohydrate Polymers, 214, 110-116 (2019).

https://doi.org/10.1016/j.carbpol.2019.03.015

[75] Lustig S. R., Peppas N. A.: Solute diffusion in swollen membranes. IX. Scaling laws for solute diffusion in gels. Journal of Applied Polymer Science, 36, 735-747 (1988).

https://doi.org/10.1002/app.1988.070360401

[76] Scherer G. W.: Hydraulic radius and mesh size of gels. Journal of Sol-Gel Science and Technology, 1, 285-291 (1994).

https://doi.org/10.1007/BF00486171

[77] Coviello T., Coluzzi G., Palleschi A., Grassi M., Santucci E., Alhaique F.: Structural and rheological characterization of scleroglucan/borax hydrogel for drug delivery. International Journal of Biological Macromolecules, 32, 83-92 (2003).

https://doi.org/10.1016/s0141-8130(03)00041-2

[78] Seidi F., Jin Y., Han J., Saeb M. R., Akbari A., Hosseini S. H., Shabanian M., Xiao H.: Self-healing polyol/ borax hydrogels: Fabrications, properties and applications. The Chemical Record, 20, 1142-1162 (2020). https://doi.org/10.1002/tcr.202000060

[79] Liu C., Lei F., Li P., Wang K., Jiang J.: A review on preparations, properties, and applications of cis-orthohydroxyl polysaccharides hydrogels crosslinked with borax. International Journal of Biological Macromolecules, 182, 1179-1191 (2021).

https://doi.org/10.1016/j.ijbiomac.2021.04.090 